\title{
Long-term follow-up of acute and chronic non-A, non-B post-transfusion hepatitis: evidence of progression to liver cirrhosis
}

\author{
G REALdi, *A AlBERTI, M RUGGE, A M RIGOLI, F TREMOLAdA, \\ L SCHIVAZAPPA, AND A RUOL
}

From the Istituto di Medicina Clinica, Cattedre di Patologia Medica e di Cardiologia dell'Università di Padova, and the Istituto di Anatomia Patologia dell'Università di Padova, Padova, Italy

SUMMARY The long-term outcome of non-A, non-B post-transfusion hepatitis was evaluated in 21 patients who developed the illness after open-heart surgery and could be followed thereafter up to five years. Histological chronic sequelae were documented in 13 patients, and consisted of chronic persistent hepatitis in one case, chronic lobular hepatitis in two and chronic active hepatitis in 10, five of whom also developed superimposed cirrhosis. Progression to these chronic states was in most cases symptomless, independently of the severity of liver lesions; one patient, however, died of gastrointestinal bleeding due to cirrhosis of the liver. During follow-up the biochemical pattern of chronic non-A, non-B hepatitis was unique, with striking fluctuations of transaminase levels. Liver histology proved essential to identify the severity of chronic liver lesions, as clinical and biochemical features were uniform and not indicative of it. Our results suggest that cirrhosis may develop, often with an asymptomatic course, in a significant number of patients who do not recover after acute post-transfusion non- $A$, non-B hepatitis.

In spite of routine screening of blood donors for hepatitis B surface antigen ( $\mathrm{HBsAg}$ ), blood recipients remain at significant risk of developing posttransfusion hepatitis that in up to $90 \%$ of the cases is unrelated to type A or B virus infection; it is therefore termed non- $A$, non-B hepatitis. ${ }^{1}$ Volunteers and animal studies have provided evidence that non-A, non-B hepatitis is caused by transmissible agents, ${ }^{2-4}$ but the possibility of identifying the infection by specific serological markers ${ }^{56}$ is still under investigation. Nevertheless, some relevant clinical features of the disease have already been described in patients with post-transfusion hepatitis in whom non- $A$, non-B infection could be diagnosed by exclusion criteria.

Prospective studies of post-transfusion hepatitis ${ }^{78}$ have shown that, although most of the patients with non-A, non-B hepatitis remain anicteric and asymptomatic, up to $50 \%$ of them may be found to have abnormal transaminase levels for longer than one year after onset, with histological evidence of signi-

*Address for correspondence: Dr Giuseppe Realdi. Istituto di Medicina Clinica. Via Giustiniani 2. Policlinico dell Università, 35100 Padova, Italy.

Received for publication 10 September 1981 ficant liver disease. Berman et al. ${ }^{9}$ have recently reported that these chronic sequelae often show a tendency towards spontaneous biochemical remission suggesting that chronic non- $A$, non-B hepatitis could be a slowly resolving rather than a chronically progressing disease. One patient in their study, however, did develop cirrhosis, and this is also documented by other authors. ${ }^{7} 1011$

We report here the long-term outcome of non-A, non-B post-transfusion hepatitis in 21 patients who developed a symptomatic disease after open-heart surgery and were followed for up to five years after onset. In seven of these patients serial liver biopsies were available during the acute phase and afterwards, giving evidence of the progression of acute disease to various histologically demonstrable chronic processes including cirrhosis of the liver.

\section{Methods}

\section{PATIENTS}

Twenty-one patients who developed non-A, non-B post-transfusion hepatitis after open-heart surgery were considered for this study. None of them showed biochemical evidence of liver disfunction before 
operation, but transaminase levels became abnormal (over three times the upper limit of the normal range) two to 12 weeks after they had received eight to 23 units of whole blood or plasma during surgery. Exposure to liver toxins, such as alcohol or drugs, and congestive heart failure could be excluded in all 21 patients whom radioimmunoassay (RIA, Abbott) showed to be HBsAg negative at repeated testing during the acute phase of the illness.

Of the 21 patients, 15 (group A) were seen in our unit during acute hepatitis, when IgM antibody to hepatitis A virus (anti-HAV) was proven negative by radioimmunoassay (Abbott) in all cases; antibody to HBsAg (anti-HBs) and antibody to hepatitis B core antigen (anti-HBc) were also negative by radioimmunoassay (Abbott) in 13 cases, while two were already anti-HBs and anti-HBc positive when they were administered. All these 15 patients underwent liver biopsy during the acute phase and were then followed up at three to six monthly intervals in our outpatient clinic. Those cases in whom transaminase levels remained raised for more than 12 months after onset underwent subsequent liver biopsies to assess the development of chronic liver disease.

The remaining six patients (group B) had been referred to our unit because abnormal transaminase levels persisted eight to 22 months after acute non-A, non-B post-transfusion hepatitis. All six patients, who were $\mathrm{HBs} \mathrm{Ag}$, anti-HBs, and anti-HBc negative by radioimmunoassay in the absence of exposure to alcohol or hepatotoxin drugs, underwent liver biopsy and were then followed up longitudinally for 17 to 32 months.

\section{HISTOLOGICAL ASSESSMENT}

Liver biopsies, which were taken after informed consent from each patient and when medical contraindications had been excluded, were interpreted according to the criteria suggested by Bianchi et al. ${ }^{1213}$ for specimens obtained during the acute phase and to those suggested by De Groote et al. ${ }^{14}$ and Popper and Shaffner ${ }^{15}$ for biopsies obtained during the chronic phase.

\section{Results}

ACUTE PHASE FEATURES AND EVOLUTION OF NON-A, NON-B POST-TRANSFUSION HEPATITIS IN 15 PATIENTS OF Group a (Table 1, Fig. 1)

A striking fluctuation in transaminase levels was noted in most patients, sometimes with normal periods between two abnormal peaks. Liver biopsies, taken two to 16 weeks after onset, showed features of classical acute hepatitis in 10 cases. In the remaining five cases spotty lobular involvement was associated with marked piecemeal necrosis and bridging necrosis, with features of acute hepatitis with possible transition to chronicity $(\mathrm{AH} / \mathrm{T}){ }^{13}$

The 15 patients were followed up prospectively for 23 to 55 months after onset. Transaminase levels became normal in seven patients, even 10 and 16 months after onset. In the remaining eight patients transaminase levels did not become consistently normal, although in most of them transient phases of normal enzyme values were recorded. As shown in Fig. 1, seven of these eight patients underwent subsequent liver biopsy that led to a diagnosis of chronic lobular hepatitis in two cases and of chronic active hepatitis in five, two of whom also showed associated cirrhotic changes.

There was no significant difference between the seven patients who recovered and those who progressed to chronic hepatitis, when several clinical and biochemical features in the acute phase were compared (Table 2). As shown in Fig. 2, the difference in alanine aminotransferase values between these two groups of patients became statistically significant after the sixth month of follow-up. Where histology

Table 1 Clinical and biochemical profile of 15 patients with acute non- $A$, non-B post-transfusion hepatitis (group A)

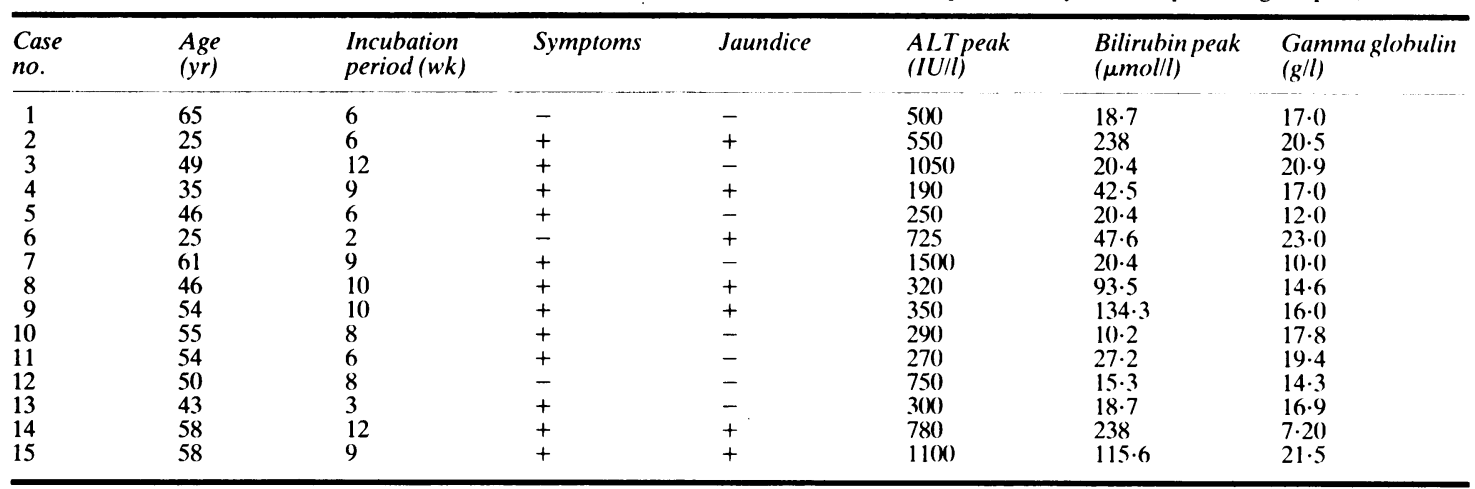




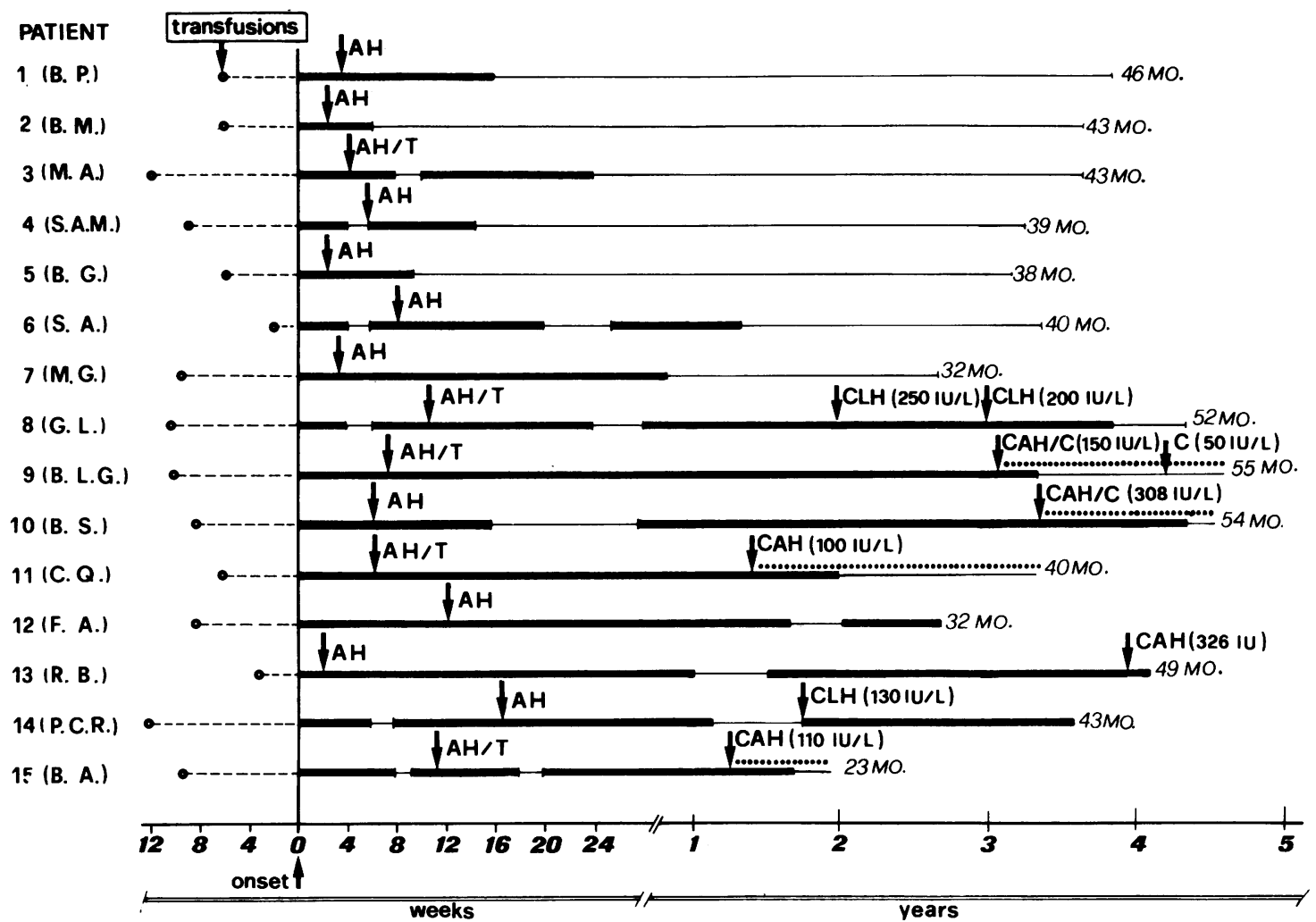

Fig. 1 Liver biopsies (arrows) and length of observation periods (months) in the 15 patients with non- $A$, non- $B$ post-transfusion hepatitis of group A. AH: classical acute hepatitis. AH/T: acute hepatitis with histological signs of possible transition to chronicity. CLH: chronic lobular hepatitis. $C A H$ : chronic active hepatitis. $C A H / C$ : chronic active hepatitis with superimposed cirrhosis. $C$ : cirrhosis with mild inflammatory activity. The values of alanine aminotransferase at the time chronic phase liver biopsies were taken are indicated in parentheses. Bold lines: periods with abnormal (more than twice the upper normal limit) enzyme levels. Fine lines: periods when enzyme levels were normal or lower than twice the upper normal limit. Dotted lines: immunosuppressive therapy.

Table 2 Acute phase clinical and biochemical findings in relation to outcome of non- $A$, non-B post-transfusion hepatitis (group A)

\begin{tabular}{lll}
\hline Parameter & \multicolumn{2}{l}{ Patients } \\
\cline { 2 - 3 } $\begin{array}{l}\text { Recovered } \\
\text { (7cases })\end{array}$ & $\begin{array}{l}\text { With chronic } \\
\text { evolution } \\
\text { (8 cases) }\end{array}$ \\
\hline Age (yr) & $43 \cdot 7 \pm 16 \cdot 1^{*}$ & $52 \cdot 2 \pm 5 \cdot 4^{*}$ \\
Incubation period $(\mathrm{wk})$ & $7 \cdot 14 \pm 3 \cdot 1^{*}$ & $8 \cdot 25 \pm 2 \cdot 7^{*}$ \\
Subjective symptoms & $4(57 \cdot 1 \%)$ & $7(87 \cdot 5 \%)$ \\
Jaundice & $3(42 \cdot 8 \%)$ & $4(50 \%)$ \\
ALT peak $(\mathrm{IU} / \mathrm{l})$ & $680 \cdot 7 \pm 462 \cdot 8^{*}$ & $520 \pm 313 \cdot 8^{*}$ \\
Bilirubin peak $(\mu \mathrm{mol} / \mathrm{l})$ & $58 \cdot 3 \pm 80 \cdot 1^{*}$ & $81 \cdot 5 \pm 80 \cdot 1^{*}$ \\
Gamma globulin $(\mathrm{g} / \mathrm{l})$ & $17 \cdot 2 \pm 4 \cdot 7^{*}$ & $15 \cdot 9 \pm 4 \cdot 2^{*}$ \\
Units of transfusion & $13 \cdot 5 \pm 5 \cdot 2^{*}$ & $15 \cdot 6 \pm 4 \cdot 8^{*}$ \\
\hline
\end{tabular}

${ }^{*}$ Mean $\pm \mathrm{SD}$. None of the considered figures reached statistical significant difference (Chi-square analysis and Cochran-Cox test) between the two groups of patients. Conventional bilirubin levels:

$\div 17 \cdot 1$. Gamma globulin: $\div 10 \cdot 1$. was concerned, the presence of piecemeal necrosis in acute phase liver biopsies was associated with an evolution to chronicity in four out of five patients. A similar outcome, however, was also observed in three out of the 10 cases with classical features of acute hepatitis on biopsy (Fig. 1).

\section{CLINICAL AND HISTOLOGICAL FEATURES IN SIX PATIENTS IN GROUP B}

When the six patients entered this study only one had symptoms, consisting of fatigue and digestive discomfort. Transaminase levels were raised in all patients with values ranging from two to seven times the upper normal limit. Liver biopsies taken 12 to 26 months after acute onset showed features of chronic persistent hepatitis in one case and of chronic active hepatitis in five cases, three having already developed superimposed cirrhotic changes (Table 3). 


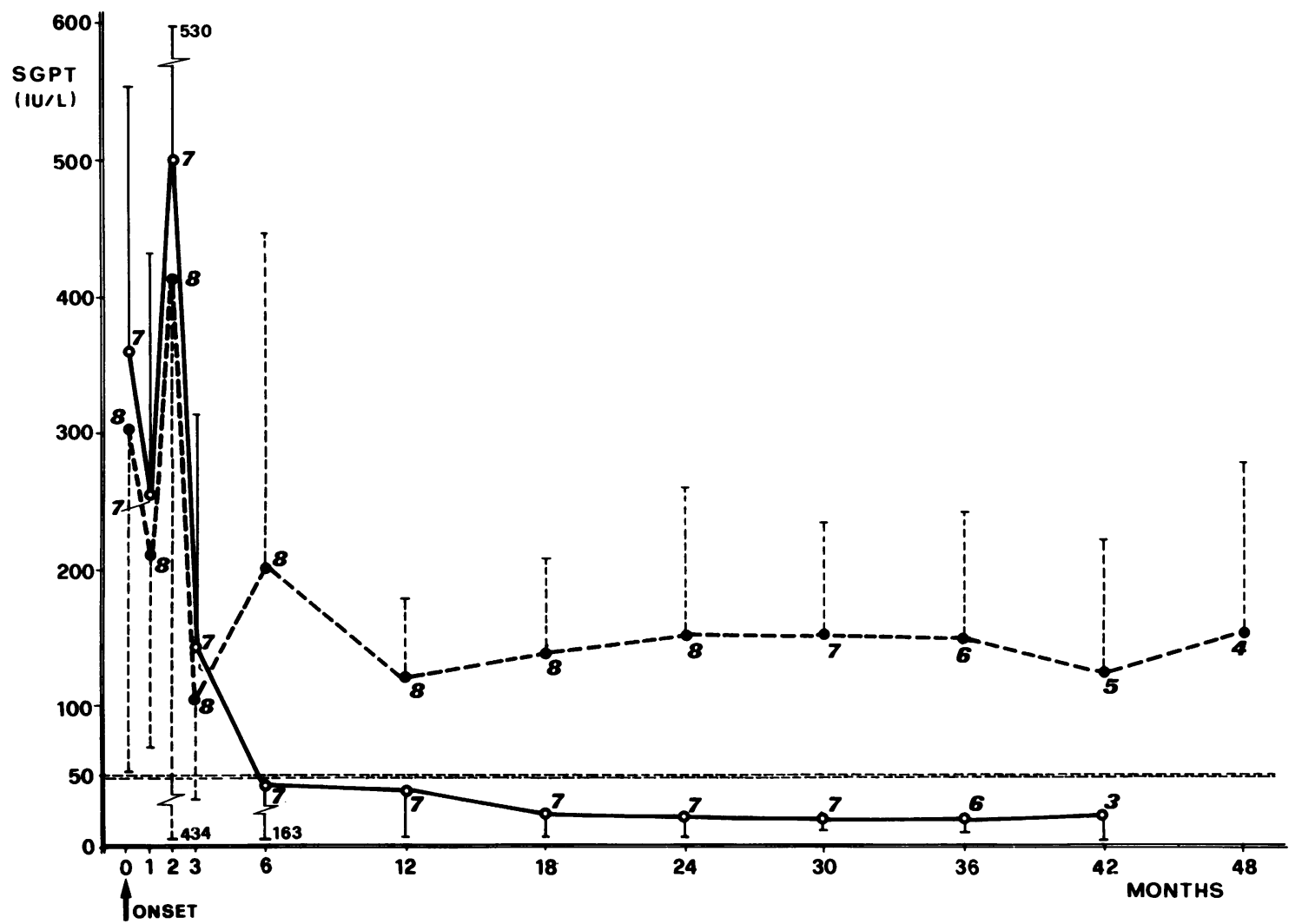

Fig. 2| Behaviour of alanine aminotransferase (mean and range) in the seven patients who recovered (continuous line) compared with that in the eight patients who progressed to chronic liver disease (broken line) of group A. The numbers near the circles indicate number of patients tested at each interval.

LONG-TERM FOLLOW-UP OF CHRONIC NON-A, NON-B HEPATITIS

The 14 patients in whom non- $A$, non-B posttransfusion hepatitis progressed to a chronic stage (eight cases in group A and six cases in group B) were followed up to 23-58 months after acute onset. Four patients complained only of mild symptoms suggestive of chronic liver disease. Nine patients, including all but one of those with cirrhosis, remained symptomless during the follow-up. Development of ascites or of encephalopathy was not observed in any of the patients. One patient (case no. 9, Fig. 1) died of gasurointestinal bleeding 18 months after the diagnosis of chronic active hepatitis with cirrhosis had been made.

The biochemical behaviour of the disease in the 14

Table 3 Histological findings in six patients of group B

\begin{tabular}{|c|c|c|c|c|}
\hline \multirow[t]{2}{*}{ Patient } & \multirow{2}{*}{$\begin{array}{l}\text { Age } \\
(y r)\end{array}$} & \multicolumn{2}{|c|}{ Liver biopsy (months after acute onset) } & \multirow{2}{*}{$\begin{array}{l}\text { Last observation- } \\
\text { months-after } \\
\text { acute onset }\end{array}$} \\
\hline & & $\begin{array}{l}\text { First and } A L T \\
(I U / l)\end{array}$ & $\begin{array}{l}\text { Subsequent and } \\
A L T(I U / I)\end{array}$ & \\
\hline $\begin{array}{l}\text { SG } \\
\text { MP } \\
\text { PG } \\
\text { FE } \\
\text { RF } \\
\text { CC }\end{array}$ & $\begin{array}{l}36 \\
57 \\
57 \\
53 \\
28 \\
52\end{array}$ & $\begin{array}{l}\mathrm{CAH}(12)-230 \\
\mathrm{CAH}(18)-200 \\
\mathrm{CAH} / \mathrm{C}(26)-320 \\
\mathrm{CAH} / \mathrm{C}(25)-260 \\
\mathrm{CPH}(16)-77 \\
\mathrm{CAH} / \mathrm{C}(17)-250\end{array}$ & $\begin{array}{l}\mathrm{CAH}(23)-19^{*} \\
\mathrm{CPH}(33)-110^{*} \\
\mathrm{CAH} / \mathrm{C}(38)-62^{*} \\
\mathrm{C}(35)-26^{*} \\
\text { (Not done) } \\
\mathrm{C}(28)-35^{*}\end{array}$ & $\begin{array}{l}39 \\
42 \\
58 \\
49 \\
41 \\
34\end{array}$ \\
\hline
\end{tabular}

$\mathrm{CAH}$ : chronic active hepatitis; $\mathrm{CAH} / \mathrm{C}$ : chronic active hepatitis with superimposed cirrhosis; $\mathrm{CPH}$ : chronic persistent hepatitis; $\mathrm{C}$ : cirrhosis with mild inflammatory activity.

*Cases on immunosuppressive therapy. 
cases, when untreated, was characterised by striking fluctuations in transaminase levels, sometimes with variable periods of normality. There was no significant difference in transaminase levels and pattern between cases with either chronic lobular hepatitis or chronic persistent hepatitis and those with more severe histological lesions.

During the follow-up, nine of the 10 patients with chronic active hepatitis were started on immunosuppressive therapy with $16 \mathrm{mg}$ /day prednisolone alone (five cases) or combined with $50 \mathrm{mg} /$ day azathioprine (four cases). The five cases who did not receive immunosuppressive drugs (two chronic lobular hepatitis, one chronic persistent hepatitis, one chronic active hepatitis, and one patient in whom liver biopsy was not available) continued to show the same pattern of transaminases and in none of them was sustained normalisation of enzymes observed. In contrast, among the nine patients started on therapy, eight showed a progressive reduction of transaminases and in seven of them enzyme levels persistently either returned to normality or, although raised, remained lower than twice the upper limit of normality. In six of these patients on immunosuppressive treatment a new liver biopsy was taken 10 to 21 months later (Fig. 1, Table 3). In two of them (one chronic active hepatitis, one chronic active hepatitis with cirrhosis) the histological diagnosis remained unchanged, while in three other patients with chronic active hepatitis and cirrhosis there was almost complete disappearance of inflammatory activity; in another patient with chronic active hepatitis regression to chronic persistent hepatitis was noted, although his alanine aminotransferase values remained abnormal.

As regards development of cirrhosis in our patients with non-A, non-B hepatitis, it was noted that cirrhotic changes had already become evident in only one out of eight patients who were biopsied one to two years after onset, compared with four out of six untreated patients biopsied at later stages (between the second and the fourth year of illness).

\section{Discussion}

Recent prospective studies of blood recipients have accumulated evidence that those patients who develop non-A, non-B post-transfusion hepatitis often progress to chronic liver disease. ${ }^{7-10}$ The long-term outcome of this chronic condition and its clinical significance, however, have not yet been determined. In this study we have observed development of histological signs of cirrhosis of the liver in five out of 14 patients who had not recovered after non-A, non-B post-transfusion hepatitis. None of these five patients had clinical or biochemical evidence of liver disease before they were transfused and in two of them acute phase liver biopsies were available and excluded preexisting chronic liver disease. Serial acute and chronic phase liver biopsies were also available in five other patients, three showing progression from acute hepatitis to chronic active hepatitis and two to chronic lobular hepatitis.

Thus, in our series of patients with non-A, non-B post-transfusion hepatitis, the long-term evolution was more severe than that suggested by previous studies, ${ }^{89}$ and included development of cirrhosis in a significant number of patients, one of whom eventually died of gastrointestinal bleeding.

Possible explanations for these discrepancies could relate to the duration of our follow-up or to the type of patients considered. Indeed, in most of our cases cirrhotic changes were noted in biopsies taken more than two years after onset, while biopsies taken at earlier stages were usually free of cirrhosis. In addition, nearly all of our patients had symptomatic acute disease, although symptoms disappeared after the acute phase in many patients who progressed to chronic hepatitis. In contrast, in published series of patients with non-A, non-B post-transfusion hepatitis, asymptomatic cases largely predominated.

These differences could indicate that symptomatic acute non-A, non-B hepatitis, unlike hepatitis B virus infection, may pursue a more severe chronic course compared with asymptomatic acute disease.

In our patients, the clinical features of the acute phase, and also most of the biochemical findings, were not indicative of the course of the illness. The presence of piecemeal necrosis in acute phase liver biopsies was highly indicative of chronic evolution, although not of its histological severity. Development of chronic liver lesions, however, including cirrhosis also occurred in three patients who had typical acute histological features in the first liver biopsy.

Serial determination of transaminase levels for a prolonged period of time represented in our patients the most reliable way of identifying chronic sequelae. As also underlined by other authors, ${ }^{19}$ the pattern of behaviour of liver enzymes was, in these patients, unique, with striking fluctuations in time including phases of normality. Sustained normality of transaminases occurred more than one year after onset in few patients who then seemed to be cured, but all those who continued to show abnormal values for more than 18 months progressed to chronic lesions. In these patients liver histology was essential in order to identify the severity of the hepatic involvement, as the clinical and biochemical pattern was not indicative of the degree of liver damage.

No conclusions can be reached on the effect of immunosuppressive therapy in our patients with 
chronic non-A, non-B hepatitis. Most patients on therapy showed improvement of transaminase levels and in some of them reduction in inflammatory activity was also noted in the liver. Clearly, however, only a controlled trial can decide whether immunosuppressive drugs are needed in chronic non-A, non-B liver disease.

This study was supported in part by a grant from the Consiglio Nazionale delle Ricerche, Rome, Italy. The authors wish to thank Miss Antonella Trivellato for editorial assistance.

\section{References}

1 Alter HJ. The dominant role of non-A, non-B in the pathogenesis of post-transfusion hepatitis. Clin Gastroenterol 1980; 9:155-70.

2 Alter HJ, Purcell RH, Holland PV, Popper H. Evidence for a transmissible agent in non- $A$, non- $B$ hepatitis. Lancet 1978; 1:459-63.

3 Tabor E, Gerety RJ, Drucker JA, Seeff LB, Hoofnagle JH, Jackson DR, April M, Barker LF, PinedaTamondong $\mathrm{G}$. Transmission of non-A, non-B hepatitis from man to chimpanzee. Lancet $1978 ; 1: 463-5$.

4 Hoofnagle JH, Gerety RJ, Tabor E, Feistone SM, Barker LF, Purcell RH. Transmission of non-A, non-B hepatitis. Ann Intern Med 1977; 87:14-20.

5 Shirachi R, Shiraishi H, Tateda A, Kikuchi K, Ishida N. Hepatitis $C$ antigen in non- $A$, non-B post-transfusion hepatitis. Lancet 1978; 2:853-6.

6 Vitvitski L, Trepo C, Prince AM, Brotman B. Detec- tion of virus-associated antigen in serum and liver of patients with non-A, non-B hepatitis. Lancet 1979; 2:1263-7.

7 Knodell RG, Conrad ME, Ishak KG. Development of chronic liver disease after acute non-A, non-B posttransfusion hepatitis: role of gammaglobulin prophylaxis in its prevention. Gastroenterology 1977; 72:902-9.

8 Koretz RL, Suffin SC, Gitnick GL. Post-transfusion chronic liver disease. Gastroenterology 1976; 71:797803.

9 Berman M, Alter HJ, Ishak KG, Purcell RH, Jones EA. The chronic sequelae of non-A, non-B hepatitis. Ann Intern Med 1979; 91:1-6.

10 Koretz RL, Stone O, Gitnick GL. The long-term course of non-A, non-B post-transfusion hepatitis. Gastroenterology 1980; 79:893-8.

11 Dienstag JL, Galdabini JJ. Liver disease after a coronary-bypass operation. $N$ Engl J Med 1980; 303:207-16.

12 Bianchi L, De Groote J, Desmet VJ, Gedigk P, Korb G, Popper H, Poulsen H, Scheuer PJ, Schmid M, Thaler H, Wepler W. Morphological criteria in viral hepatitis. Lancet 1971; 1:333-7.

13 Bianchi L, De Groote J, Desmet VJ, Gedigk P, Korb G, Popper H, Poulsen H, Sheuer PJ, Schmid M, Thaler H, Wepler W. Acute and chronic hepatitis revisited. Lancet 1977; 2:914-9.

14 De Groote J, Desmet VJ, Gedigk P, Korb G, Popper H, Poulson H, Sheuer PJ, Schmid M, Thaler H, Uehlinger E, Wepler W. A classification of chronic hepatitis. Lancet $1968 ; 2: 626-8$.

15 Popper H, Schaffner F. The vocabulary of chronic hepatitis. N Engl J Med. 1971; 284:1154-6. 